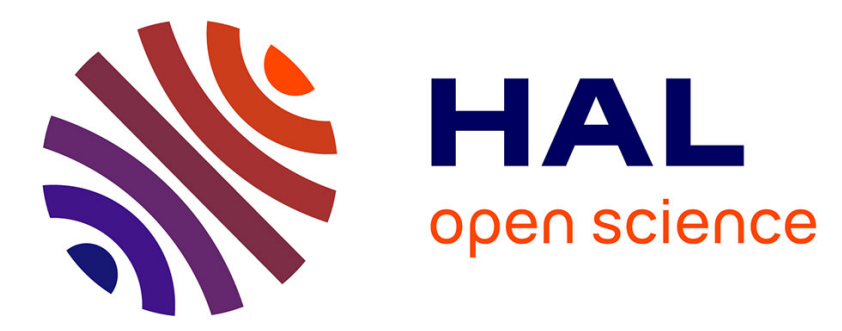

\title{
Tungsten oxide thin film bombarded with a low energy He ion beam: evidence for a reduced erosion and $\mathrm{W}$ enrichment
}

Céline Martin, H. Hijazi, Y. Addab, B. Domenichini, M. E. Bannister, F. W. Meyer, C. Pardanaud, G. Giacometti, M. Cabié, P. Roubin

\section{To cite this version:}

Céline Martin, H. Hijazi, Y. Addab, B. Domenichini, M. E. Bannister, et al.. Tungsten oxide thin film bombarded with a low energy He ion beam: evidence for a reduced erosion and $\mathrm{W}$ enrichment. Physica Scripta, 2017, T170, 10.1088/1402-4896/aa89c1 . hal-01795177

\section{HAL Id: hal-01795177 https://hal.science/hal-01795177}

Submitted on 18 May 2018

HAL is a multi-disciplinary open access archive for the deposit and dissemination of scientific research documents, whether they are published or not. The documents may come from teaching and research institutions in France or abroad, or from public or private research centers.
L'archive ouverte pluridisciplinaire HAL, est destinée au dépôt et à la diffusion de documents scientifiques de niveau recherche, publiés ou non, émanant des établissements d'enseignement et de recherche français ou étrangers, des laboratoires publics ou privés. 


\title{
Tungsten oxide thin film bombarded with a low energy He ion beam: evidence for a reduced erosion and $W$ enrichment.
}

\author{
C. Martin ${ }^{1}$, H. Hijazi ${ }^{1}$, Y. Addab ${ }^{1}$, B. Domenichini ${ }^{2}$, M. E. Bannister ${ }^{3}$, F. W. Meyer ${ }^{3}$, C. \\ Pardanaud $^{1}$, G. Giacometti ${ }^{1}$, M. Cabié ${ }^{4}$ and P. Roubin ${ }^{1}$ \\ ${ }^{1}$ Aix-Marseille Univ, CNRS, PIIM, UMR 7345, Marseille F-13397, France \\ ${ }^{2}$ University Bourgogne Franche-Comté, CNRS, UMR 6303, Lab Interdisciplinaire Carnot \\ Bourgogne, Dijon F-21078, France \\ ${ }^{3}$ Physics Division, Oak Ridge National Laboratory, Oak Ridge, TN 37831-6372, USA \\ ${ }^{4}$ Aix-Marseille Univ, CP2M, Marseille F-13397, France \\ E-mail: celine.martin@univ-amu.fr
}

\begin{abstract}
Nanocrystalline tungsten oxide $\left(\mathrm{WO}_{3}\right)$ thin films synthesized by thermal oxidation of tungsten substrates were exposed to low energy helium ions (energy: $80 \mathrm{eV}$; flux: $1.4-1.7 \times 10^{20} \mathrm{~m}^{-2} \mathrm{~s}^{-1}$ ) at room temperature and at $673 \mathrm{~K}$. The structure and morphology changes of the oxide were studied using Raman spectroscopy and electron microscopy. Due to the low ion energy, no erosion is observed at room temperature. On the contrary, at $673 \mathrm{~K}$, a colour change is observed and a significant erosion is measured $(\sim 70 \mathrm{~nm}$ for a fluence of $\sim 4 \times 10^{21} \mathrm{~m}^{-2}$ ) due to a synergetic effect between ion bombardment and heating. We show that erosion processes and structural changes strongly depend on the ion fluence and in particular the higher the fluence, the lower the erosion yield, most likely due to oxygen depletion in the oxide near-surface layers.
\end{abstract}

Keywords: tungsten oxide, thin film, He ion bombardment, erosion, Raman spectroscopy, electron microscopy, sputtering yield.

\section{Introduction}

Because of its favourable physical properties, tungsten is the material used for plasma facing components (PFCs) receiving the highest fluxes in operating tokamaks (ASDEX-upgrade, JET-ILW, WEST) [1-3] and will compose the ITER divertor [4]. However, tungsten has a strong chemical affinity with oxygen and native oxide is naturally present on tungsten surfaces [5, 6]. On PFCs, tungsten oxide $\left(\mathrm{WO}_{3}\right.$ or $\mathrm{WO}_{3-\mathrm{x}}$ ) can be formed due to oxygen contamination, to PFCs high temperature (a few hundred 
degrees) and in case of accidental scenarios [7, 8]. Oxidation will induce a modification of tungsten wall properties especially regarding the erosion yield, the reflectivity and the deuterium retention $[7,8]$, which will depend on the structure, the stoichiometry and the thickness of the oxide layers formed [9]. For example, considering the first wall cladding for which ELMs induce erosion by melted layer movement and melted droplet ejection, erosion could occur more easily and on larger area. Considering the divertor, erosion and retention properties can also be changed. Oxide layer erosion contributes to additional sources of $\mathrm{W}$ in the discharge and deuterium is retained more easily in tungsten oxide than in tungsten due to the formation of bronzes [11].

In this paper, we investigate the mechanisms of erosion of thin tungsten oxide films under $\mathrm{He}$ bombardment at low energy and low fluence. In a previous study, we have found evidence of a major thermal enhancement of the erosion yield after low energy $(20 \mathrm{eV})$ and low fluence $\left(410^{21} \mathrm{~m}^{-2}\right) \mathrm{He}$ plasma exposure at $673 \mathrm{~K}$ while only limited changes of tungsten oxide films were observed at room temperature [10]. Note that the film behaviour under He plasma bombardment is distinct from that under D plasma bombardment with similar energy and fluence, for which a plasma-chromic effect has been observed [11], emphasizing the role of chemical reactivity in the case of deuterium. Here, samples have been exposed to a $80 \mathrm{eV} \mathrm{He}$ ion beam at room temperature and $673 \mathrm{~K}$, and changes in the structure, the thickness and the erosion yield have been studied as a function of the He ion fluence by means of Raman spectroscopy, Focused Ion Beam technique (FIB) and Scanning Electron Microscopy (SEM) and Transmission Electron Microscopy (TEM).

\section{Experimental}

Polycrystalline rolled tungsten produced by Goodfellow with a purity of $99.95 \mathrm{wt} \%$ and polycrystalline recrystallized tungsten produced by ALMT with a purity of $99.99 \mathrm{wt} \%$ were used as substrates. The grain structure was a major difference between these substrates, grain size being about a few micrometers and a few tens of micrometers for Goodfellow and ALMT, respectively. These substrates were electrochemically polished to a mirror-like surface using a 1.5 at. $\% \mathrm{NaOH}$ solution, and cleaned in ultrasonic baths with acetone and ethanol. The substrates were outgassed at $10^{-5} \mathrm{~Pa}$ and $673 \mathrm{~K}$ during 4 hours and then oxidized at $673 \mathrm{~K}$ under an oxygen pressure of $5.910^{4} \mathrm{~Pa}$ during 4 hours. We thus produced two nanocrystalline monoclinic $\mathrm{WO}_{3}$ films $\left(\gamma-\mathrm{WO}_{3}\right)$.

Film thicknesses were measured by SEM on a FIB cross-section (using the FEI Helios 600 NanoLab Dual Beam apparatus) and found before exposure to be $116 \pm 4 \mathrm{~nm}$ and $56 \pm 4 \mathrm{~nm}$ for the Goodfellow and ALMT samples, respectively. Thicker layers with a higher crystalline quality were obtained for Goodfellow substrates than for ALMT substrates, showing that the grain structure plays a role in the oxide formation. The films were blue-cyan and blue in colour due to interference phenomena. 
Structural analysis was made by TEM on slices $(\sim 100 \mathrm{~nm})$ cut perpendicular to the sample surface by FIB using a FEI Tecnai G2 with an acceleration voltage of $200 \mathrm{kV}$. Raman spectra were recorded in the range $100-1100 \mathrm{~cm}^{-1}$ using a Horiba-Jobin-Yvon HR LabRAM microscope $(\lambda=514 \mathrm{~nm}$, resolution $\approx 1$ $\mathrm{cm}^{-1}$, laser spot size $\approx 1 \mu \mathrm{m}^{2}$, laser power $\approx 4 \mathrm{~mW} \mu \mathrm{m}^{-2}$ ). X-ray Photoelectron Spectroscopy (XPS) experiments performed with a VG CLAM4 photoelectron spectrometer using a monochromatized $\mathrm{Al} \mathrm{K} \alpha$ X-ray source.

Helium ion bombardments were performed at the Oak Ridge National Laboratory (ORNL) Multicharged Ion Research Facility [12] using the new high-current beam deceleration module of the CAPRICE ECR ion source beamline described in [13]. To determine the ion flux distribution, a positively biased $(+27 \mathrm{~V})$ beam catcher inside an enclosure with a $1 \mathrm{~mm}^{2}$ aperture that can be scanned across the ion beam was recently installed [14] and accurate flux profiles were measured prior to each oxide film exposure. The He ion energy was $80 \mathrm{eV}$ and $28 \mathrm{~s}$ exposures were performed at room temperature on the ALMT sample and at $673 \mathrm{~K}$ on the Goodfellow sample (flux at maximum: 1.5 and $1.710^{20} \mathrm{~m}^{-2} \mathrm{~s}^{-1}$, respectively). Heating was performed using electron bombardment and the pressure in the chamber was kept at $\sim 410^{-5} \mathrm{~Pa}$ during the exposures.

\section{Results and discussion}

Figure 1 shows the Raman spectra in the stretching region $\left(500-1100 \mathrm{~cm}^{-1}\right)$ of the tungsten oxide films (blue lines) before and (red lines) after He ion exposure, at room temperature (figure 1a) and at 673 $\mathrm{K}$ (figure $1 \mathrm{~b}$ ). Insets show the images of the ion beam spot, the dark lines corresponding to engraved markers. At room temperature, the sample colour is unchanged whereas at $673 \mathrm{~K}$ it has turned after exposure to magenta on a large area, remaining blue at the center of the beam spot (lower-left of the marker cross). Before exposure, the Raman spectra of the two samples show the two W-O stretching bands at around 700 and $800 \mathrm{~cm}^{-1}$ typical of $\gamma$-WO3 [15-17]. The additional minor band at $960 \mathrm{~cm}^{-1}$ is frequently observed and attributed to local defects generating $\mathrm{W}=\mathrm{O}$ terminal bonds [18, 19].

After exposure at room temperature, the Raman spectrum is very similar to that before exposure, indicating a negligible effect of the ion bombardment. On the contrary, at $673 \mathrm{~K}$, the bands at $\sim 700$ and $800 \mathrm{~cm}^{-1}$ significantly broaden and the band at $960 \mathrm{~cm}^{-1}$ increases drastically. These observations suggest the creation of disorder and defects such as $\gamma-\mathrm{WO}_{3}$ network distortion and $\mathrm{W}-\mathrm{O}$ bond breaking [20]. The most intense Raman band shifts from 807 to $825 \mathrm{~cm}^{-1}$, indicating the oxide reduction by the creation of Ovacancies [21]. Similar observations are reported in [10] in the case of a He plasma bombardment at 673 $\mathrm{K}$ where, despite the low ion energy $(20 \mathrm{eV})$ a significant erosion has been measured and thus a major effect of temperature in the erosion process evidenced. In what follows, erosion at $673 \mathrm{~K}$ is analyzed in more details. 


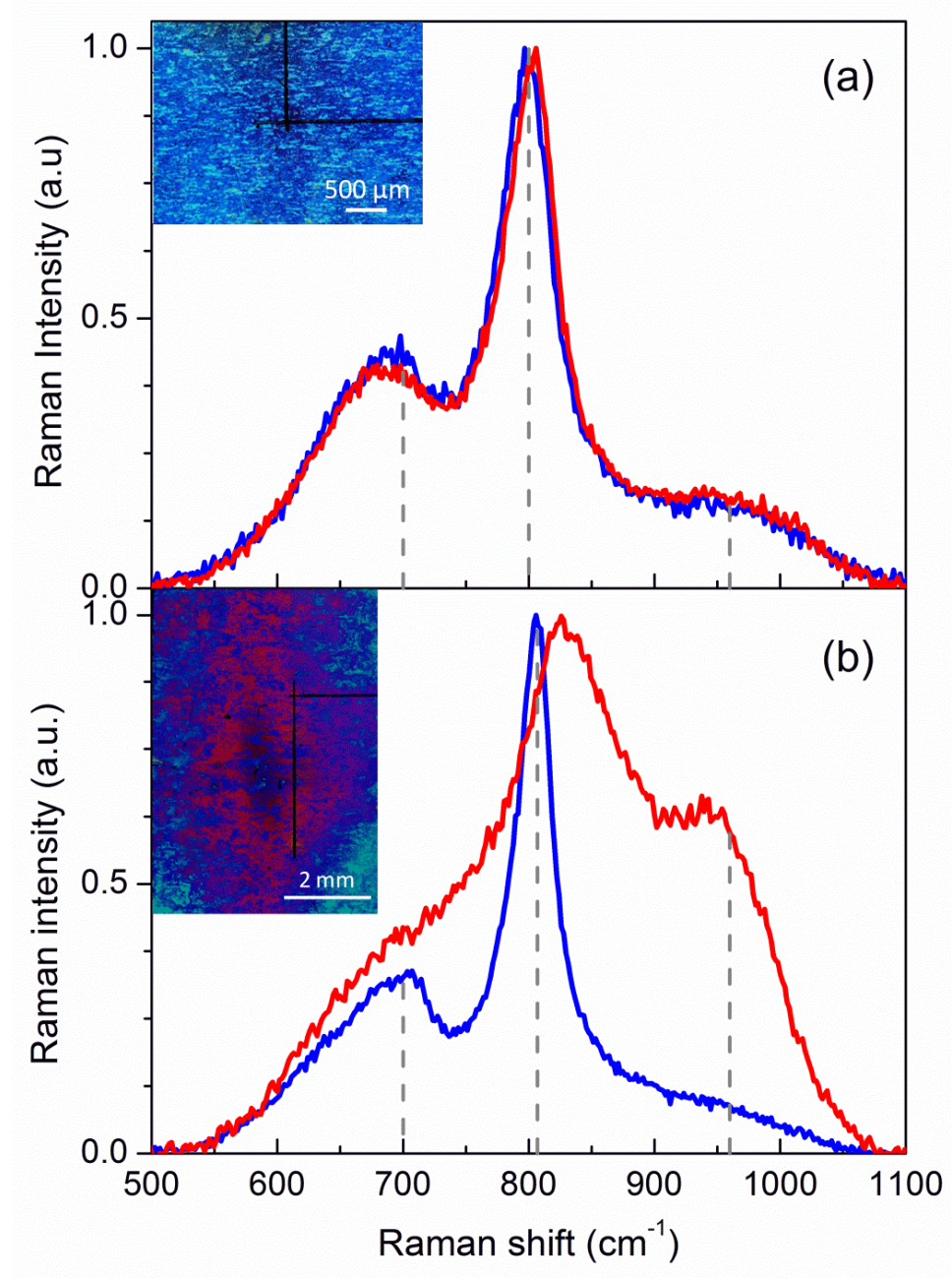

Figure 1: Raman spectra of tungsten oxide samples (blue lines) before exposure and (red lines) after an exposure to a He ion beam (ion energy: $80 \mathrm{eV}$, duration: $28 \mathrm{~s}$ ): (a) at room temperature (flux max: $1.510^{20} \mathrm{~m}^{2} \mathrm{~s}^{-1}$ ) and (b) at $673 \mathrm{~K}$ (flux max: $1.710^{20} \mathrm{~m}^{2} \mathrm{~s}^{-1}$ ). Images of the exposed part of the samples are displayed in the insets, dark lines are engraved markers. 


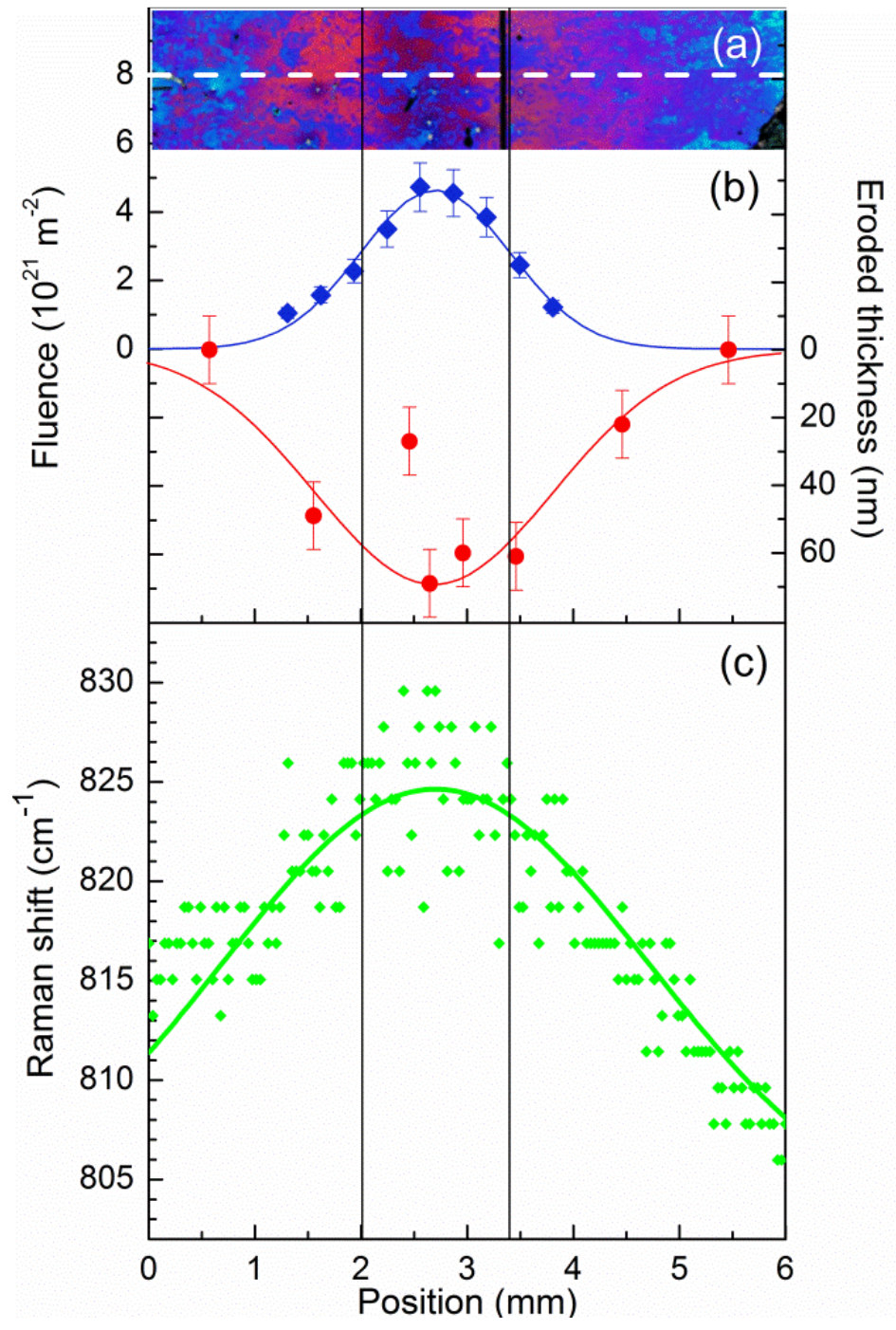

Figure 2: Experimental profiles of tungsten oxide bombarded with a $80 \mathrm{eV} \mathrm{He}$ ion beam at $673 \mathrm{~K}$ (a) image of the sample (b) ion beam fluence profile (blue diamonds, left hand scale) and eroded thickness (red circles, right hand scale) along the white dashed line (c) Raman shift of the main $\mathrm{WO}_{3}$ peak (observed at $807 \mathrm{~cm}^{-1}$ before exposure). Vertical lines are guide for eyes at the half height of the ion fluence profile. Continuous coloured lines are Gaussian fits.

Figure 2 shows (a) the image of the sample after exposure at $673 \mathrm{~K}$ centered on the beam spot center (this is a part of the image of the inset of figure 1b), (b) the beam flux profile along the white dashed line as measured by the beam catcher set-up described in the experimental part and the eroded thickness profile as measured on several points using FIB and SEM, and (c) the profile of the most intense Raman peak position. Except for one point, the erosion profile is regular and the maximum thickness loss at the beam spot center is $70 \mathrm{~nm}$. As in the case of He plasma bombardment at $20 \mathrm{eV}$, the heated sample is significantly eroded. 
The Raman peak also regularly shifts from $807 \mathrm{~cm}^{-1}$ far from the spot center to $825 \mathrm{~cm}^{-1}$ at the center, indicating that the higher the fluence, the more reduced the oxide. The three profiles can be fitted by Gaussians (continuous lines), their full width at half-maximum (FWHM) being 1.4, 2.2 and $4.0 \mathrm{~mm}$ respectively. In particular, the Raman profile is significantly broader than those of the ion flux or the eroded thickness. The image also shows a colour change from blue to magenta on a wide zone, much larger than the ion flux profile FWHM. Far from the beam spot center, the flux is low and erosion negligible, the colour change is thus due to changes in absorption properties caused by defects such as Ovacancies. At the beam spot center, the thickness is low enough to make absorption negligible and the blue colour due to interference remains dominant.

The erosion yield $\left(\mathrm{WO}_{3} / \mathrm{He}\right)$ is estimated using the relation $\rho \times \mathrm{N}_{\mathrm{A}} \times \delta /(\mathrm{M} \times \mathrm{F})$ where $\mathrm{N}_{\mathrm{A}}$ is the Avogadro constant, $\rho$ and $\mathrm{M}$ are the layer density and molar mass of $\mathrm{WO}_{3}$, respectively, and $\delta$ is the measured eroded thickness at fluence F. Figure 3 shows that it decreases with increasing fluence $F$ as $F^{-\alpha}$, with $\alpha \sim$ 0.6 . The lowest erosion yield at the beam spot center (flux: $1.710^{20} \mathrm{~m}^{-2} \mathrm{~s}^{-1}$ ) is at $0.27 \pm 0.11$. Note that the erosion yield reported in [10] is $0.1 \pm 0.05$ and therefore, the erosion process seems to present energy dependence.

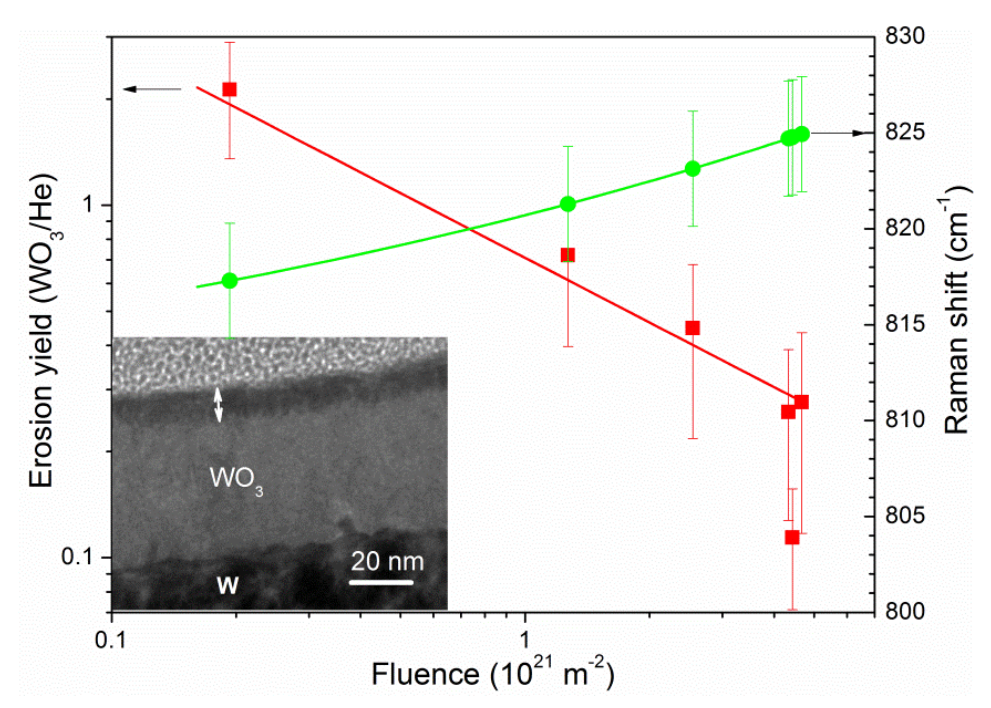

Figure 3: $\mathrm{WO}_{3}$ thin film after He ion beam exposure at $673 \mathrm{~K}$ (ion energy: $80 \mathrm{eV}$, fluence: $410^{21} \mathrm{~m}^{-2}$; duration: $28 \mathrm{~s}$ ): (a) Erosion yield $\left(\mathrm{WO}_{3} / \mathrm{He}\right.$ ) and (b) Raman shift of the main peak at $\sim 800 \mathrm{~cm}^{-1}$ versus the He beam fluence. Red points are calculated (see text) from the measured values of eroded thickness (red points of figure 2) using the corresponding Gaussian values of fluence. Red and green continuous lines are deduced from the Gaussian fits of figure 2. Green points merely highlight the values obtained for the fluence values of red data points. Inset: TEM image of a slice cut close to the beam spot center showing a damaged layer at the oxide film surface. 
The erosion yield decrease is correlated with the increase of the Raman shift displayed in figure 3 showing that the lower the yield, the more reduced the oxide. This is also in agreement with the TEM image obtained at the beam spot center (in the inset) which shows a $10 \mathrm{~nm}$ damaged layer at the oxide film near-surface [10, 22], its darker contrast being explained by the $\mathrm{W}$ enrichment (higher $\mathrm{Z}$ contrast). Similar $\mathrm{WO}_{3}$ reduction due to the preferential sputtering of oxygen under ion bombardment has been previously observed [23, 24]. In the case of the $20 \mathrm{eV}$ He ion bombardment [10], a clear evidence of the reduction of $\mathrm{WO}_{3}$ after $\mathrm{He}$ exposure at $673 \mathrm{~K}$ was obtained using XPS experiments. The spectra measured for $\mathrm{WO}_{3}$ exposed at room temperature and at $673 \mathrm{~K}$ are displayed in figure 4 in the $\mathrm{W} 4 \mathrm{f}$ binding energy region. The two samples show mainly the hexavalent tungsten signature of $\mathrm{W}$ in $\mathrm{WO}_{3}\left(\mathrm{~W}^{6+}\right)$ with the two main peaks measured at 38.2 and $36.1 \mathrm{eV}$ and attributed to $\mathrm{W} 4 \mathrm{f}_{5 / 2}$ and $\mathrm{W}_{4} \mathrm{f}_{7 / 2}$, respectively. However, shoulders related to components at lower binding energies and with lower intensities are also observed and should be attributed to $\mathrm{W}^{5+}$ and, possibly, to $\mathrm{W}^{4+}$ components. Decompositions of $\mathrm{W} 4 \mathrm{f}$ region spectra are offered using a branching ration between $5 / 2$ and $7 / 2$ components of 0.75 and a spin-orbit splitting of 2.1 $\mathrm{eV}$. In the case of the exposure at RT, a good fit is obtained using an additional doublet measured at 36.3 and $34.2 \mathrm{eV}$. The peak intensity ratio $\mathrm{W}^{5+} / \mathrm{W}^{6+}$ allows to conclude to the presence of $8 \%$ of $\mathrm{W}^{5+}$ in the superficial layers, i.e. a global oxide stoichiometry as $\mathrm{WO}_{2.96}$. In the case of the exposure at $673 \mathrm{~K}$, a third doublet at 34.6 and $32.5 \mathrm{eV}$ related to $\mathrm{W}^{4+}$ should be considered to reach a good fit revealing $68 \%$ of $\mathrm{W}^{6+}$, $14 \%$ of $\mathrm{W}^{5+}$ and $18 \%$ of $\mathrm{W}^{4+}$. Such peak intensity ratios leads to the stoichiometry of the oxide as $\mathrm{WO}_{2.75}$. These results confirm that the surface top most layers are significantly reduced after the bombardment at $673 \mathrm{~K}$, as the TEM image contrast was interpreted.

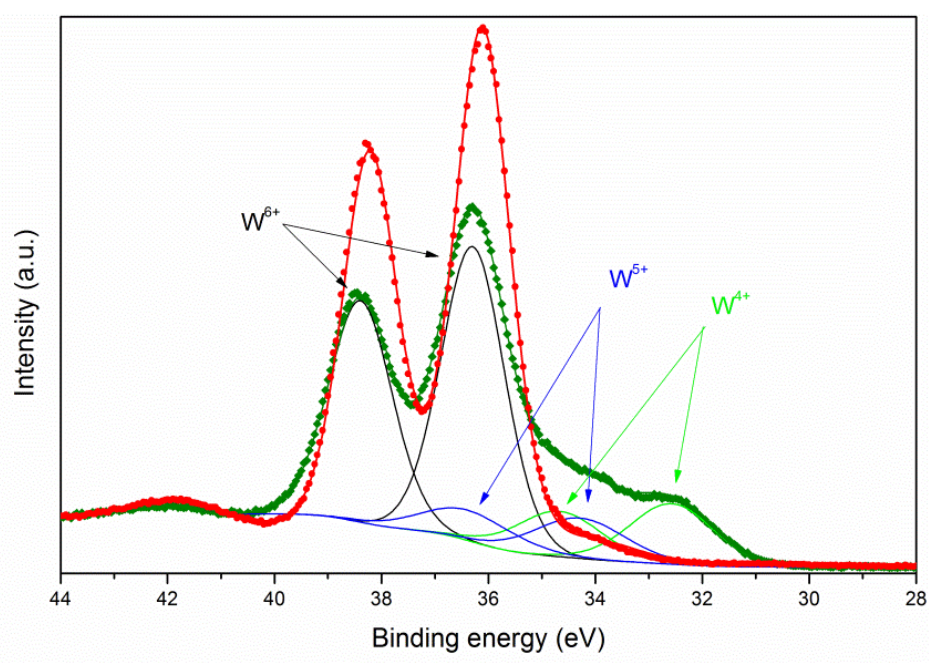

Figure 4: XPS W4f spectra of $\mathrm{WO}_{3}$ thin films after He ion beam exposure at room temperature (red circles) and at $673 \mathrm{~K}$ (green diamonds) (ion energy: $20 \mathrm{eV}$, fluence: $410^{21} \mathrm{~m}^{-2}$; duration: $27 \mathrm{~min}[10]$ ). 
The sputtering efficiency depends on the element mass, being low for heavy elements in the case of light projectiles such as $\mathrm{He}$, and, for mixed material with light and heavy elements, the proportion of heavy elements increases to the detriment of light elements. The material content is then continuously changed during the bombardment, the heavy element enrichment inducing a decrease of the erosion yield. Raman,TEM and XPS observations give thus a consistent picture for interpreting the reduced erosion yield as being due to $\mathrm{O}$ depletion and consequent $\mathrm{W}$ enrichment leading to a less efficient erosion process. Reduced sputtering yields due to surface enrichment in tungsten have been previously observed in the case of steels where $\mathrm{W}$ is a minor component [25-27] and it is observed here for the first time in the case of tungsten oxide.

\section{Conclusion}

Nanocrystalline tungsten oxide $\left(\mathrm{WO}_{3}\right)$ thin films produced by thermal oxidation of tungsten substrates were exposed to low energy $\mathrm{He}$ ions $(80 \mathrm{eV})$ during $28 \mathrm{~s}$ with a flux in the range of $10^{20} \mathrm{~m}^{-2} \mathrm{~s}^{-1}$ at the maximum of the beam spot, at room temperature and at $673 \mathrm{~K}$. At room temperature, no erosion is observed while at $673 \mathrm{~K}$ the film thickness has significantly decreased, $\sim 70 \mathrm{~nm}$ at maximum, corresponding to an erosion yield $\left(\mathrm{WO}_{3} / \mathrm{He}\right)$ of $0.27 \pm 0.11$. We have measured a decrease of the erosion yield when the fluence increases and we have shown that preferential loss of oxygen and consequent $\mathrm{W}$ enrichment of the near-surface layer is a key process. This study clearly shows that $\mathrm{WO}_{3}$ erosion due to ion bombardment at low ion energy and at temperature well below $\mathrm{WO}_{3}$ sublimation temperature is a complex process which cannot be explained by only sputtering with binary collisions and which involves synergetic mechanisms such as bond breaking, O-vacancies formation and desorption of the resulting tightly-bonded $\mathrm{WxOy}$ species of the near-surface layer due to heating. Further experiments at various sample temperatures and ion energies are needed to fully analyze the role of temperature in the activation of the erosion mechanisms and to determine the erosion threshold.

\section{Acknowledgements}

This work was carried out within the framework of EUROfusion Consortium and received funding from the Euratom research and training programme 2014-2018 under grant agreement No 633053. The views and opinions expressed herein do not necessarily reflect those of the European Commission. It was also supported by the A*MIDEX project (no ANR-11-IDEX-0001-02) sponsored by the "Investissements d'Avenir" French Government programme, managed by the French National Research Agency (ANR). 


\section{References}

[1] C. Bourdelle, J. F. Artaud, V. Basiuk, M. Becoulet, S. Bremond, J. Bucalossi, H. Bufferand, G. Ciraolo, L. Colas, Y. Corre, X. Courtois, J. Decker, L. Delpech, P. Devynck, G. Dif-Pradalier, R. P. Doerner, D. Douai, R. Dumont, A. Ekedahl, N. Fedorczak, et al. Nuclear Fusion 201555063017

[2] G. Ritz, T. Hirai, P. Norajitra, J. Reiser, R. Giniyatulin, A. Makhankov, I. Mazul, G. Pintsuk and J. Linke Physica Scripta 2009 T138 014064

[3] K. Sugiyama, M. Mayer, V. Rohde, M. Balden, T. Durbeck, A. Herrmann, S. Lindig, A. Wiltner, H. W. Muller, R. Neu, A. U. Team Nuclear Fusion 201050035001

[4] G. Federici, P. Andrew, P. Barabaschi, J. Brooks, R. Doerner, A. Geier, A. Herrmann, G. Janeschitz, K. Krieger, A. Kukushkin, A. Loarte, R. Neu, G. Saibene, M. Shimada, G. Strohmayer, M. Sugihara Journal of Nuclear Materials 200331311 Pii s0022-3115(02)01327-2

[5] C. Beleznai, D. Vouagner and J. P. Girardeau-Montaut Surface \& Coatings Technology 1998100445

[6] E. A. Hodille, F. Ghiorghiu, Y. Addab, A. Zaloznik, M. Minissale, Z. Piazza, C. Martin, T. Angot, L. Gallais, M. F. Barthe, C. S. Becquart, S. Markelj, J. Mougenot, C. Grisolia, R. Bisson Nuclear Fusion 201757076019

[7] J. P. Coad, E. Alves, N. P. Barradas, A. Baron-Wiechec, N. Catarino, K. Heinola, J. Likonen, M. Mayer, G. F. Matthews, P. Petersson, A. Widdowson, J.-E. Contributors Physica Scripta 2014 T159 014012

[8] R. Neu, C. Hopf, A. Kallenbach, T. Putterich, R. Dux, H. Greuner, O. Gruber, A. Herrmann, K. Krieger, H. Maier, V. Rohde Journal of Nuclear Materials 20073671497

[9] J. Roth, J. Bohdansky and W. Ottenberger Data on Low Energy Light Ion Sputtering 1979 Report IPP 9/26, Max-Planck-Institut für Plasmaphysik, Garching

[10] H. Hijazi, Y. Addab, A. Maan, J. Duran, D. Donovan, C. Pardanaud, M. Ibrahim, M. Cabie, P. Roubin and C. Martin Journal of Nuclear Materials 201748491

[11] Y. Addab, C. Martin, C. Pardanaud, J. Khayadjian, K. Achkasov, D. Kogut, G. Cartry, G. Giacometti, M. Cabie, J. L. Gardarein, P. Roubin Physica Scripta 2016 T167 014036

[12] F. W. Meyer, M. E. Bannister, J. W. Hale, C. C. Havener, H. F. Krause, C. R. Vane, S. Deng, I. N. Dragani and P. R. Harris Proceedings of XIX Int. ECR Workshop, Grenoble 2010 Available from:http://accelconf.web.cern.ch/AccelConf/ECRIS2010/papers/mocobk04.pdf.

[13] H. Hijazi and F. W. Meyer Review of Scientific Instruments 201384033305 
[14] M. E. Bannister, H. Hijazi, H. M. Meyer, V. Cianciolo and F. W. Meyer Nuclear Instruments \& Methods in Physics Research Section B-Beam Interactions with Materials and Atoms 201433975

[15] D. Davazoglou, A. Donnadieu, R. Fourcade, A. Hugotlegoff, P. Delichere and A. Perez Revue De Physique Appliquee 198823265

[16] F. D. Hardcastle and I. E. Wachs Journal of Raman Spectroscopy 199526397

[17] E. Cazzanelli, C. Vinegoni, G. Mariotto, A. Kuzmin and J. Purans Journal of Solid State Chemistry 199914324

[18] M. Boulova and G. Lucazeau Journal of Solid State Chemistry 2002167425

[19] A. Baserga, V. Russo, F. Di Fonzo, A. Bailini, D. Cattaneo, C. S. Casari, A. L. Bassi and C. E. Bottani Thin Solid Films 20075156465

[20] R. Sivakumar, C. Sanjeeviraja, M. Jayachandran, R. Gopalakrishnan, S. N. Sarangi, D. Paramanik and T. Som Journal of Physics D-Applied Physics 200841125304

[21] G. L. Frey, A. Rothschild, J. Sloan, R. Rosentsveig, R. Popovitz-Biro and R. Tenne Journal of Solid State Chemistry 2001162300

[22] C. Martin, R. Ruffe, C. Pardanaud, M. Cabie, C. Dominici, T. Dittmar, P. Languille, B. Pegourie, E. Tsitrone and P. Roubin Journal of Nuclear Materials 2011415 S258

[23] T. J. Driscoll, L. D. McCormick and W. C. Lederer Surface Science 1987187539

[24] G. Leftheriotis, S. Papaefthimiou, P. Yianoulis and A. Siokou Thin Solid Films 2001384298

[25] J. Roth, K. Sugiyama, V. Alimov, T. Hoschen, M. Baldwin and R. Doerner Journal of Nuclear Materials 20144541

[26] V. K. Alimov, Y. Hatano, N. Yoshida, H. Watanabe, M. Oyaidzu, M. Tokitani and T. Hayashi Nuclear Materials and Energy 2016725

[27] S. Brezinsek, J.W. Coenen, T. Schwarz-Selinger et al. Nuclear Fusion 201757116041 